\title{
PRE-EXISTING WEATHER PHENOMENA FOR SPREADING DENGUE FEVER OVER DHAKA IN 2019
}

\author{
Shahanaj Sultana ${ }^{1 *}$, Md. Abdul Mannan ${ }^{1}$, Md. Abdur Rahman Khan ${ }^{1}$, Ronakey Khandaker ${ }^{1}$ and Md. \\ Kamrujjaman ${ }^{2}$ \\ ${ }^{1}$ Bangladesh Meteorological Department, Agargaon, Sher-E-Bangla Nagar, Dhaka - 1207 \\ ${ }^{2}$ Bangladesh Jute Mill Corporation, Adamjee Court Annex-1, 115-120, Motijheel, Dhaka - 1000
}

Received: 12 June 2020

Accepted: 01 December 2020

\begin{abstract}
An attempt has been made to investigate the outbreak of dengue fever over Dhaka city by examining the preexisting condition of weather elements over Bangladesh. For the study, the maximum temperature, minimum temperature, rainfall, humidity data is analyzed to find the optimum values which trigger the dengue fever over Dhaka city. If the pre-existing weather phenomena are analyzed and compute, it will be possible to settle down which elements are responsible for spreading dengue fever over Dhaka city in 2019. The average minimum and maximum temperature were relatively high in winter season of 2019 than that of the winter of 2018 which may trigger epidemic dengue fever. In June increased temperature and intermittent rainfall (260mm within 17 days) which is also causes of spreading dengue. This is why, Dhaka city, 51,777 dengue cases have occurred from 1 st January to 31 December 2019 on the other hand 50,726 dengue cases had occurred during 2000-2018. In the future, due to climate change and its unstable weather phenomena, weak administrator, unplanned urbanization, environmental erosion, and increasing population, dengue risk will be high. If Dhaka city people are not conscious, dengue may increase more upcoming years due to the possibility of increasing temperature, the occurrence of abnormal rainfall, the environmental condition of Dhaka city, and attack trend of previous years.
\end{abstract}

Kew words: Aedes; Dengue; Humidity; Rainfall; Temperature.

\section{INTRODUCTION}

Dengue is a viral infectious disease. It is occurred by the bite of an infected female Aedes mosquito Directorate General of Health Services (DGHS), 2018. Infants, young children, and adults affected more by dengue fever. Many researchers agreed with World Health Organization (WHO) those mosquito-borne viral diseases (dengue $\&$ severe dengue) are spreading out all over the world especially in tropical \& subtropical regions (Choi et al., 2016; Li et al., 2020; Hossain et al., 2020). Kader et al. (2020) comments dengue is a systemic and dynamic infectious disease which may be asymptomatic or present. Some researchers (Atique et al., 2018; Emiliana et al., 2019; Shil, 2019) described four types of dengue which are DENV-1, DENV-2, DENV-3, and DENV-4. These four types are not similar in different counties in sense of severity. Normally DENV2 and DENV3 types are affected more in southern Asia. DENV-1 and DENV-2 are in circulation more of this decade in Dhaka. The high frequency of severe dengue cases correlates with the prevalence of serotype DENV-3 in 2019 according to the comments of Arifa Akram (2019). But DENV2 is normal dengue but lack of care it may be severe type. DENV1 is severe than DENV3. Infecting serotype was identified in 469 dengue-confirmed patients comprising $22.0 \%$ dengue virus serotype 1 (DENV-1), 57.1\% DENV-2, 17.1\% DENV-3, and 3.8\% DENV-4 which are showed Chee-Fu Yung et al., (2015). Dengue viruses are having three structural proteins and seven nonstructural proteins (https://www.nature.com). Structural proteins are capsid (C), envelope (E), and membrane (M) proteins. NS1, NS2A, NS2B, NS3, NS4A, NS4B, NS5 are nonstructural proteins (Yusha Araf et al., 2020). NS1 means (non-structural protein 1) the patient has dengue although the severity can't be confirmed by this test. These also have a lot of genesis. Bangladesh is confirmed of dengue diseases. The outbreaks center is Dhaka, but its cases have been reported from all over the country. Officially Dhaka (Mamun et al., 2019) has recently experienced an upsurge of dengue incidence with 8-9 years cyclical epidemic pattern since 2000 (especially 2000, 2001, 2002, 2004 and 2015-19) during the period of 2000-2019. But in 2019 Bangladesh experienced the worst dengue fever outbreak (Rahman et al., 2020; Hossain et al., 2020; Noor, 2020). Dengue affects $35^{\circ} \mathrm{N}$ and $35^{\circ} \mathrm{S}$ countries from the equator but nowadays all over the world it's spread at urban \& density places (Mutsuddy et al., 2019) except Antarctica. There are different types of mosquitos in Asia. Among them, the common mosquitos are Anopheles, Culex, Aedes, and Mansonides. There are four types of Aedes mosquito. All of the Aedes mosquitoes are species or genus of Aedes: (i) The primary dengue (Riad et al., 2020) vector is the Aedes aegypti, (ii) Aedes albopictus (secondary dengue vector), (iii) Aedes polynesiensis, and (iv) Aedes scutellarin. Aedes aegypti \& Aedes albopictus carry the dengue virus more. In Dhaka city, Aedes aegypti is 
more than Aedes albopictus but Aedes polynesiensis \& scutellarin have a limited ability to serve as dengue vectors. Aedes cannot survive any types of severe weather conditions like more heatwave (without water), more cold waves, more wind speeds, etc. Aedes can fly 15-25 ft or more (up to the fourth floor or more). But without wind \& breeding time mosquitoes are found in tree holes 50 feet above the ground. They are even found thriving in high rise apartment buildings. Abandoned overhead tanks containing even 1 inch of stagnant water is an ideal breeding spot for dengue. Dengue mosquitoes can be found to breed as high as 8000 feet in the Himalayas and as low as 2000 feet below ground in the mines (www. Leisure, Mosquito. Demystified and www. Quora, how high can a dengue mosquito fly?).

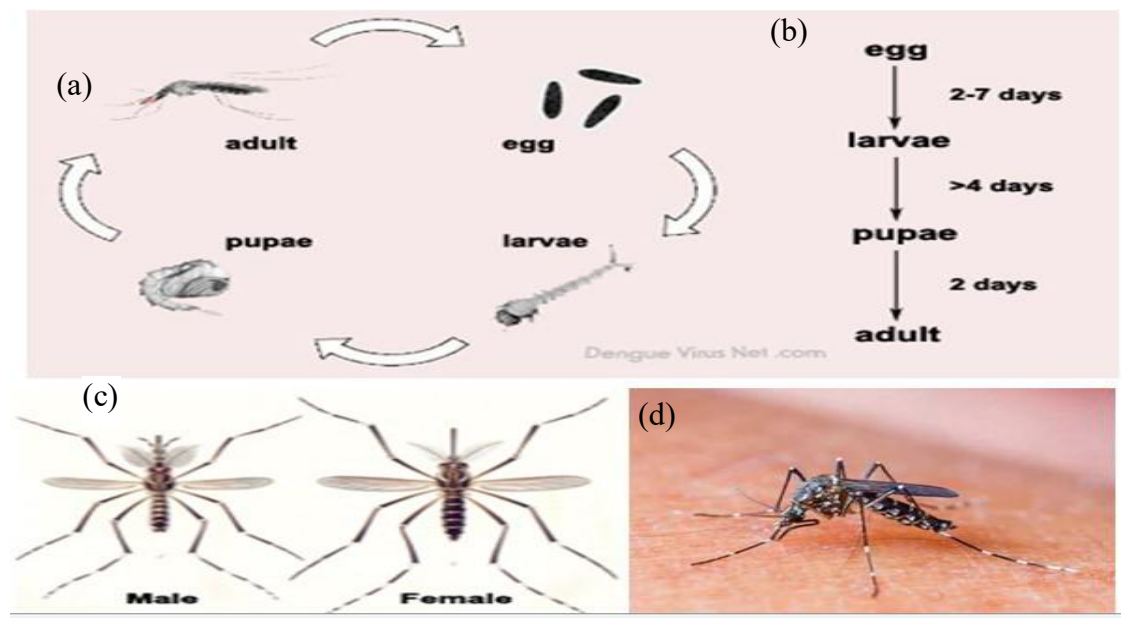

Figure 1: Life cycle of Aedes aegypti (www. Dengue virus net.com)

Aedes aegypti is habituated to breed surrounding human dwellings and likes to lay eggs in clean water where no other species are available. These eggs become adults in about one-and-a-half to two weeks. Normally male mosquitoes do not bite humans or animals. They live on fruits also. Using a microscope, male mouthparts are seen nectar feeding and female mouthparts are modified for blood-feeding - just red color (Figure 1a). Basically, female needs blood to mature her eggs. Females are bigger than males. It can be distinguished by small palps tipped with silver or white scales (www.denguevirusnet.com).

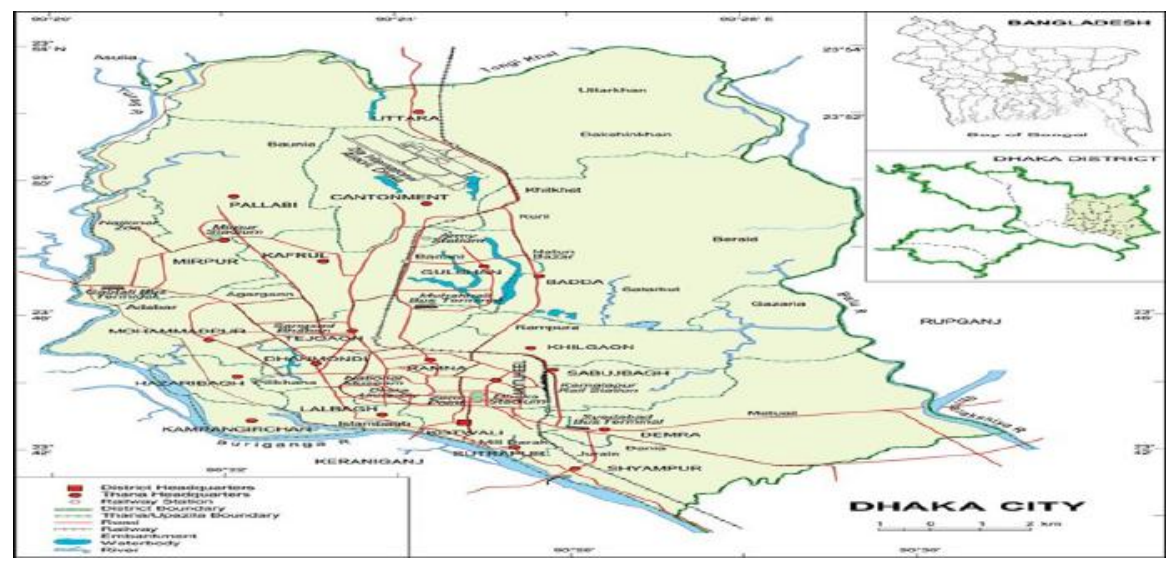

Figure 2: Location of Dhaka city in Bangladesh (www.Research Gate, Administrative map of Dhaka city)

Due to geographical location and climate change and most densely populated areas like Dhaka city are being affected by various types of vector-borne diseases like dengue and chikungunya. The objectives of this paper are "To examine the relationship of weather factors in dengue years, to know the dengue germination time of the season for understanding the weather condition and to know the cause of epidemic dengue increasing in 2019".

\section{DATA AND METHODOLOGY}

All information about Dengue (2000 to 2019) is collected from DGHS. Temperature, Humidity, Rainfall of Dhaka are collected from BMD during 2000 to 2019. But climatological data have been used from 1979 to 2018 (40 years). Daily, weekly, Monthly, Meteorological season \& dengue season (July to October) data has been used which are analyzed by Microsoft Excel. The recorded dengue data is not formative to advance analysis. 
Missing data are replaced by normal data for temperature, rainfall \& humidity but missing dengue data are replaced by some data which data are according to serial of that year followed by other years. There are four meteorological seasons in Dhaka. They are Pre-monsoon (March-May), Monsoon (June-September), PostMonsoon (October-November), and Winter (December-February).

In the recent few years, the capital city of Bangladesh is started to affect severely by many diseases like dengue, chekungunya, etc. which spread out all over the country. Chekungunya and dengue are responsible for the causalities and sometimes for disabilities. Dhaka is the most densely populated capital city where 23,234 people/square kilometers live. The latitude $23^{\circ} 40^{\prime} \mathrm{N}$ to $23^{\circ} 54^{\prime} \mathrm{N}$ and longitude $90^{\circ} 20^{\prime} \mathrm{E}$ to $90^{\circ} 31^{\prime} \mathrm{E}$ are Dhaka city (World Population Review, 2020). Dhaka has a tropical climate with two main monsoon seasons, the southwest monsoons and northeast monsoon. The geographical location of Dhaka affected by the dengue fever is depicted in Figure 2.

\section{RESULT AND DISCUSSION}

\subsection{Monthly maximum and minimum temperature, rainfall, and Dengue fever over Dhaka City area}

Comparison of average maximum and minimum temperature \& monthly rainfall of Dhaka city during 19792018 is shown in Figure 3a. The maximum temperature is gradually increasing and it continues with slight variation up to October. It has been seen that these times, April shows the highest maximum temperature of $33.9^{\circ} \mathrm{C}$. After April, the temperature decreases slightly and again it increases till October. From April to October, July is the average maximum temperature because in July more rainfall recorded than that of other months. The average minimum temperature in January is $13.2^{\circ} \mathrm{C}$ whereas the average highest minimum is $26.5^{\circ} \mathrm{C}$ in August. The highest monthly average rainfall of Dhaka is about $382.6 \mathrm{~mm}$ in July and the lowest is about $7 \mathrm{~mm}$ in January.

Comparison of average monthly temperature, rainfall, and dengue data of Dhaka from 2013 to 2019 is shown in Figure $3 \mathrm{~b}$. It shows when temperature, rainfall is rising, dengue case is also rising. It also shows the highest rainfall occurred in July and the highest amount of dengue is occurred in August with a value of 4297. Actually, the highest average dengue case occurred in September but the figure shows it in August due to the huge number of dengue case occurred in 2019.
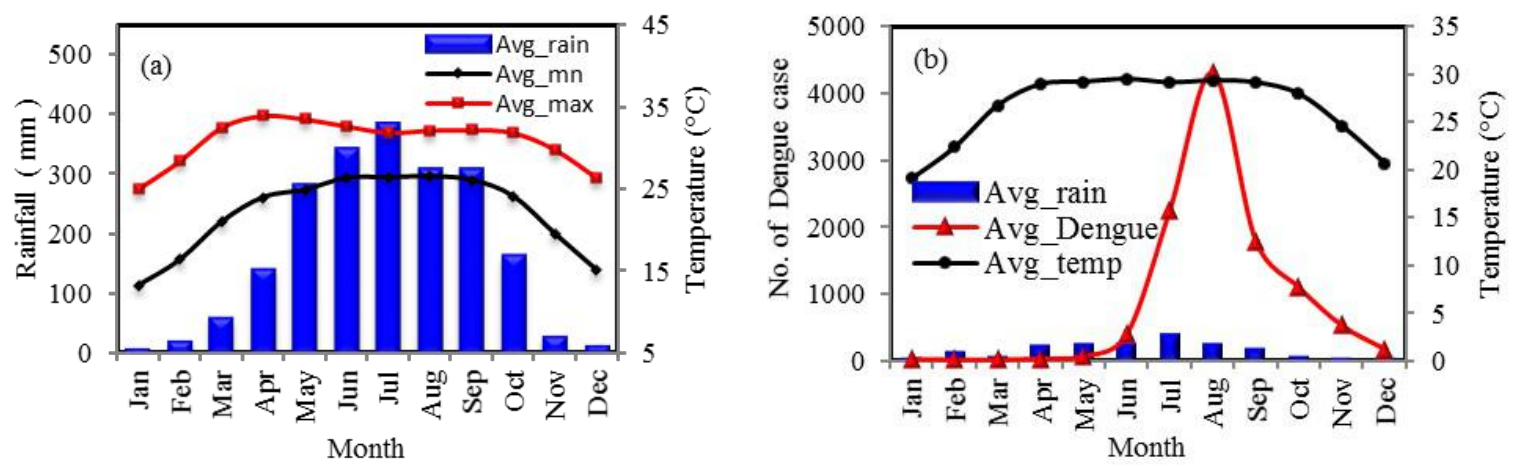

Figure 3: Monthly average (a) maximum temperature, minimum temperature and rainfall and (b) Rainfall, Temperature and Dengue case of Dhaka City

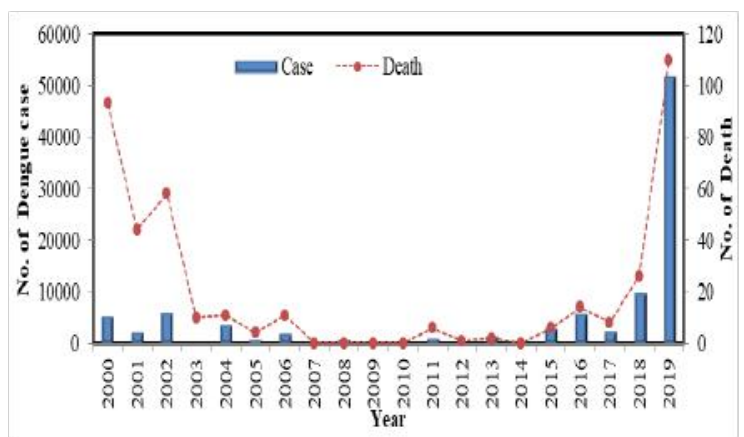

Figure 4: Yearly Dengue Case and Dengue Death 
The scenario of yearly dengue cases and death in 2019 is shown in Figure 5 which is similar to Figure 4. The graph shows the last five years case is more than the first five years case, on the other hand, the first years' death rate is more than the last five years because of human awareness \& improvement of health services. It also shows the first year (dengue starting year) death rate is more than in other years. But the middle of some year's dengue case is less than the first and last some years case. Increasing dengue case of 2019 is break record i.e. in 2019 case $(51,777)$ is more than summation of previous all year's case $(50,726)$. From figure the descending order of 20 years case are 2019, 2018, 2002, 2016, 2000, 2004, 2015, 2017, 2001 2006, 2013, 2011, 2008, 2005, $2012,2003,2009,2007,2010$, and 2014. It is also remarkable that heat wave and cold wave years of (2014, 2010, 2007, 2009, and 2003) were less dengue case occurred in Dhaka city.

\subsection{Temporal variation of daily temperature and rainfall of May and June of 2018 and 2019}

Daily rainfall and temperature of May and June in 2019 and 2018 are shown in Figures 5(a-d). Figures 5(a-c) visualize, middle of June dengue case has been increased when the temperature is increased and intermittent rainfall has been recorded. But when rainfall was occurring in May, dengue has not been so raised. At the same pattern of 2018 which is shown in Figures 5(b-d). The source of water is the precondition for the germination of dengue fever and the rainfall may trigger the dengue cases.
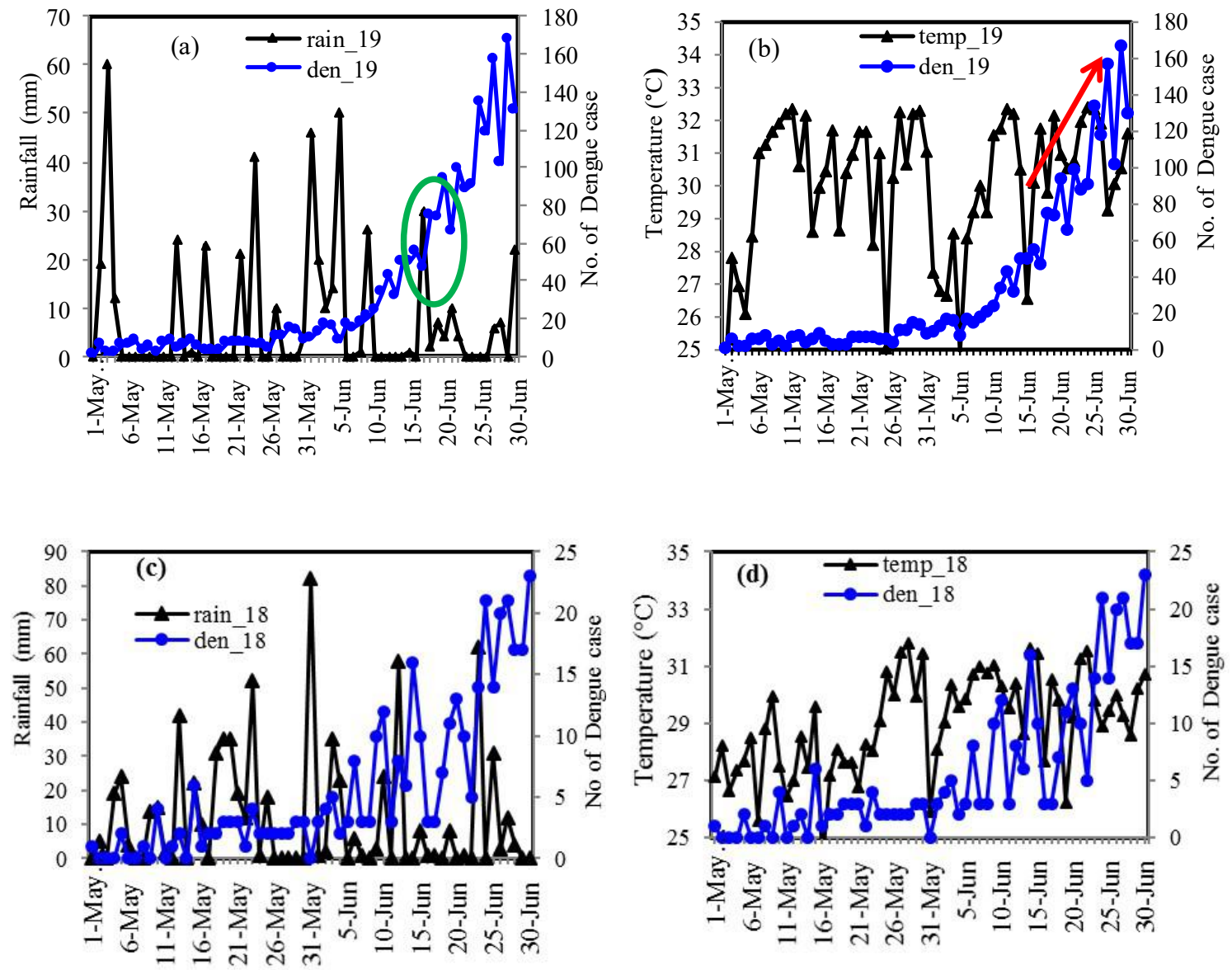

Figure 5: Daily rain and temperature with dengue case during (a-b) May to June of 2019 and (c-d) May to June of 2018

\subsection{Weekly variation of Dengue Case and Weather parameters in 2019}

The weekly dengue case in terms of temperature and rainfall during 2019 is shown in Figure 6 (a-b). Figure 6a represents the outbreak of dengue fever due to consecutive rainfall and reached the peak position when maximum rainfall occurred afterward it started to decreases. Figure $6 \mathrm{~b}$ represents, the weekly average temperature was less effective for increasing dengue in 2019 in Dhaka city. 

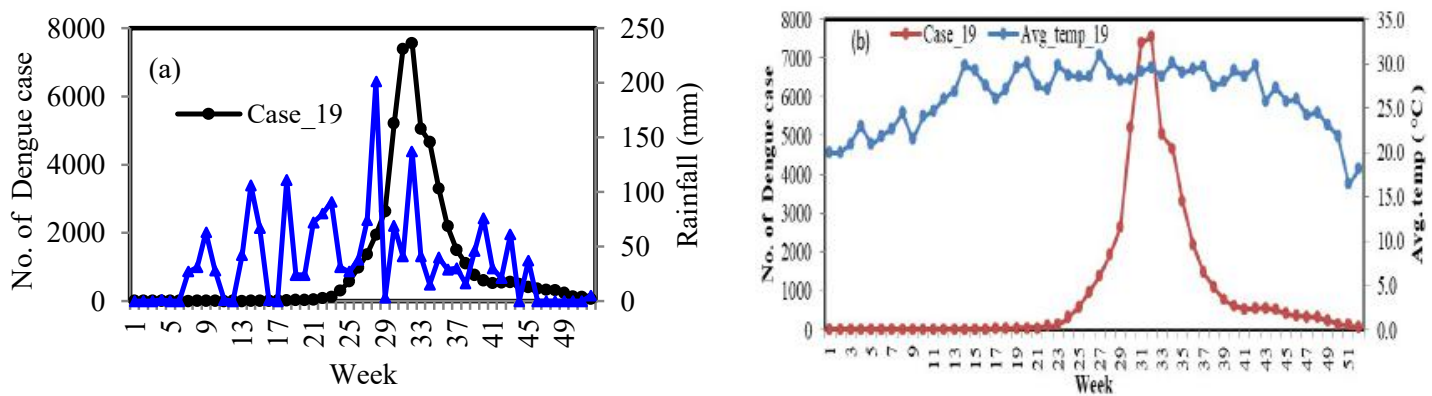

Figure 6: Weekly dengue behavior with (a) rain and (b) temperature of 2019

\subsection{Variation of Weather Parameters in 2014 and 2019}

From studies, it is found that the maximum dengue cases spread in 2019, and the least cases were found in 2014. So, the atmospheric condition of 2019 is compared with 2014. The maximum and minimum temperature in 2014 was more than that of 2019 and recently 2014 has experienced extreme temperature conditions $\left(\geq 36^{\circ} \mathrm{C}\right)$ and less rainfall occurred and, in this condition, there is a challenge to survive the Aedes mosquito growth. But in 2019 highest average maximum temperature was in the range of $(32-34)^{\circ} \mathrm{C}$ which is favorable for Aedes germination and in January of 2019 the lowest minimum temperature was nearly $12^{\circ} \mathrm{C}$ leading by the least number of cold waves whereas in 2014 it was nearly $10.3^{\circ} \mathrm{C}$ and the maximum number of cold wave occurred. So, the meteorological condition is favorable for surviving the Aedes species in 2019 presented in Figures 7(ab). From Figures $7(\mathrm{c}-\mathrm{d})$ it is clear that in pre-monsoon high amount of rainfall and its associated relative humidity was found maximum in 2019 compared to 2014 which is accountable for the growth of Aedes mosquito and afterward epidemic dengue fever over Dhaka city and adjoining area.
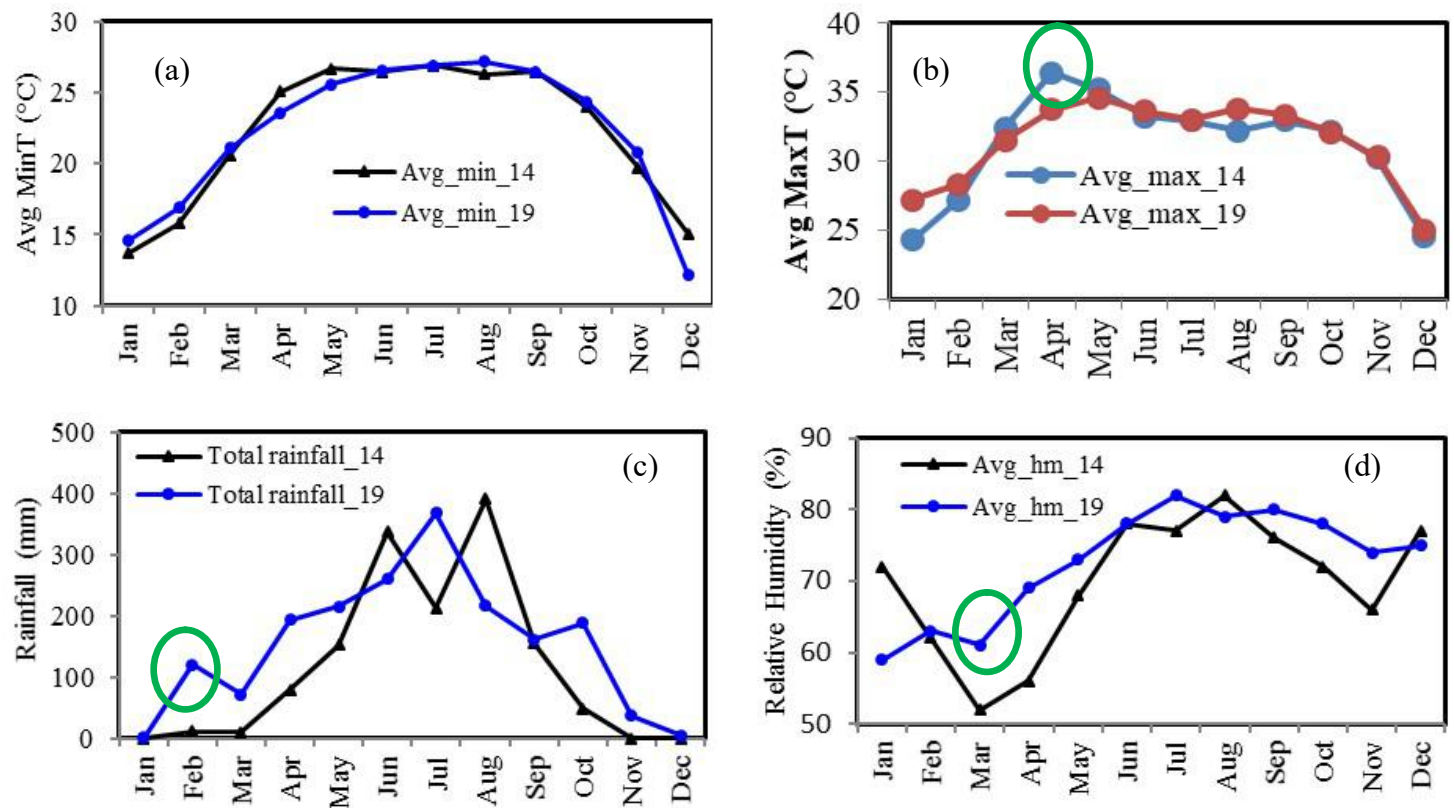

Figure 7: Monthly average (a) minimum temperature, (b) maximum temperature, (c) Rainfall and (d) Relative humidity of 2014 and 2019

\subsection{Trend analysis for temperature}

The 40 years trend analysis of the average temperature of Dhaka from 1979 to 2018 has been shown in Figure 8. The analysis shows that the average temperature has an increasing trend of the magnitude of $0.8^{\circ} \mathrm{C}$ in 40 years. This rate of the increasing trend may be responsible for mosquito growth over Dhaka city.

\subsection{Corelation between Dengue Cases Vs. Weather Parameters}

Plots of dengue cases for daily Maximum Temperature (MaxT) in 2019 reveals that dengue cases have mostly occurred when the MaxT lies between $20-37^{\circ} \mathrm{C}$ at Dhaka according to Figures $9(\mathrm{a}-\mathrm{b})$. Similarly, dengue cases 
are observed to record when Minimum Temperature (MinT) recorded with the range of $25-30^{\circ} \mathrm{C}$ at Dhaka. Figures 9(c-d) expresses that dengue cases display more during light to moderate $(25 \mathrm{~mm})$ rainfall. The figure also visualizes that the more the humidity the more dengue cases. At the same condition like 2016, 2017 and 2018 which is not visualized because of the same conditions almost lies every year.

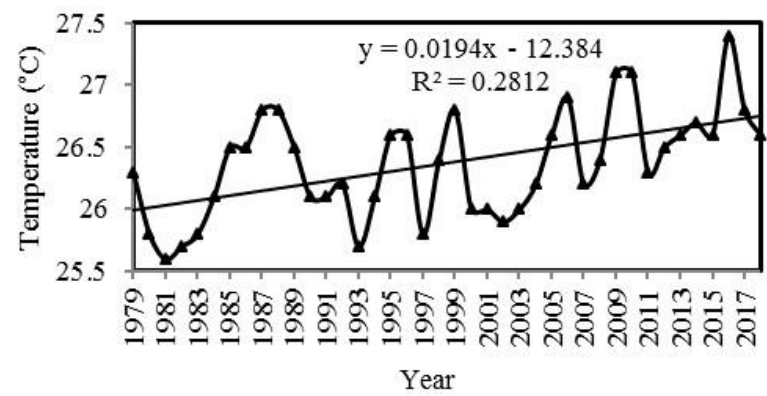

Figure 8: Trend analysis for average temperature in Dhaka city
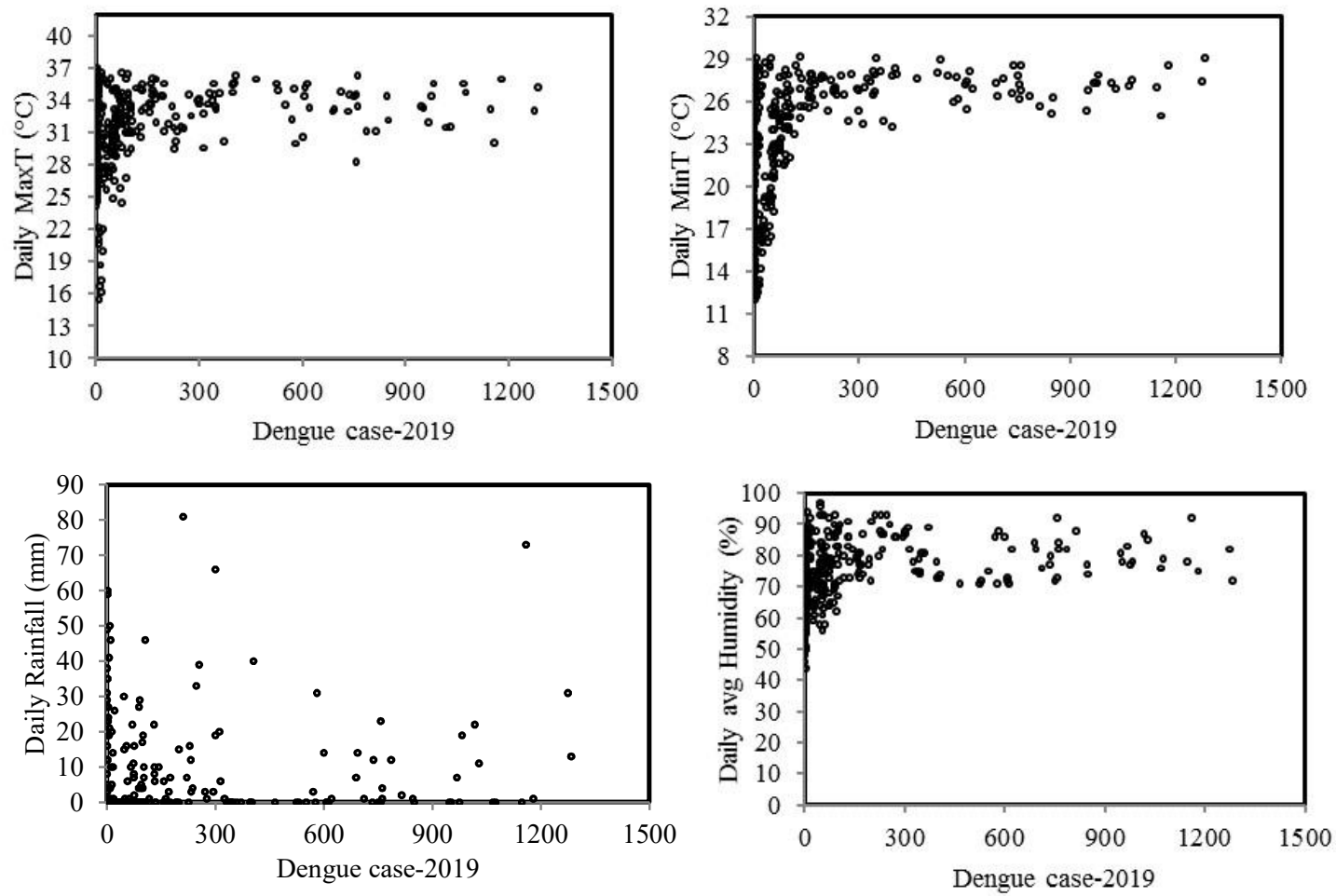

Figure 9: Variation of daily dengue case with daily (a) maximum temperature, (b) minimum temperature, (c) rainfall and (d) average humidity in 2019
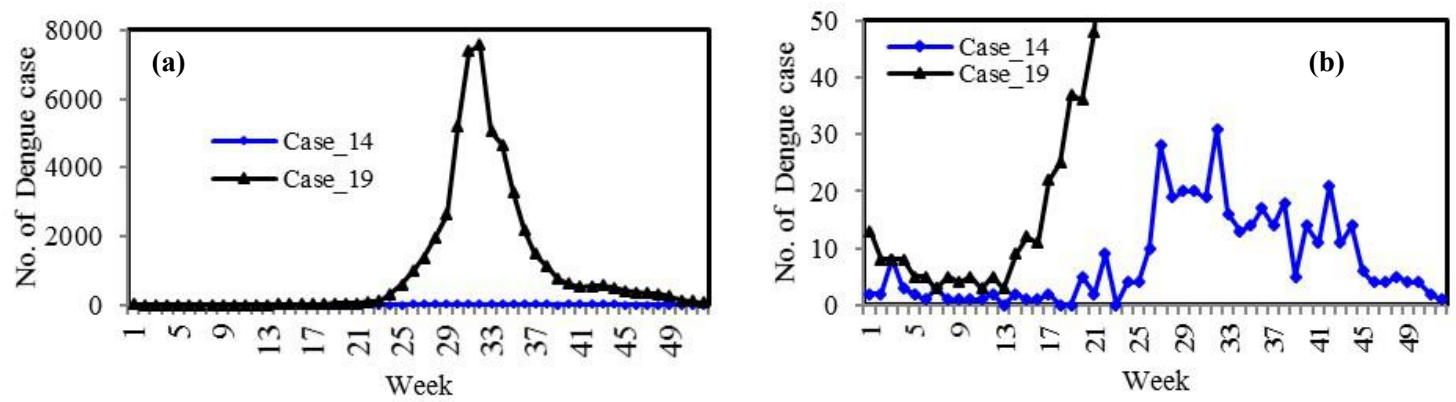

Figure 10: Comparison of weekly (a) dengue case 2014 and 2019 and (b) magnification of figure (a) 


\subsection{Variation of the number of Dengue case in recent years}

The number of dengue cases is compared to recently 2014 and 2019 years cases. Due to the huge number of cases in 2019 which has not been shown in Figures 10(a-b). This is why figure ' $a$ ' has been magnified on the right side in Figure 10b. 31 weeks of 2014 represented more dengue affected cases (31 no.) whereas 32 weeks in 2019 represented more numbers, 7561 compared to 2014. When 2014 make visible, from 22 weeks of 2019 is invisible because all of the values are above 50 which is shown in Figure $10 \mathrm{~b}$.

\subsection{Temporal Variation of Dengue case and death}

The temporal variation of dengue events and death has been showed in Figure 11c which is magnified in Figures 11(a-b). These figures are the depiction of which month and year are the most effective of dengue fever. In 2019 of August maximum number (25161) of cases occurred and other years the least number of cases found. The Figures 11(a-b) shows that dengue case of 2018, 2016 and 2015 and 2013 lower than that of 2019 it has an increasing trend. Quamrul et al. (2015) mentioned that large spatial variation of the rate of change of monsoon rainfall was found over Bangladesh.
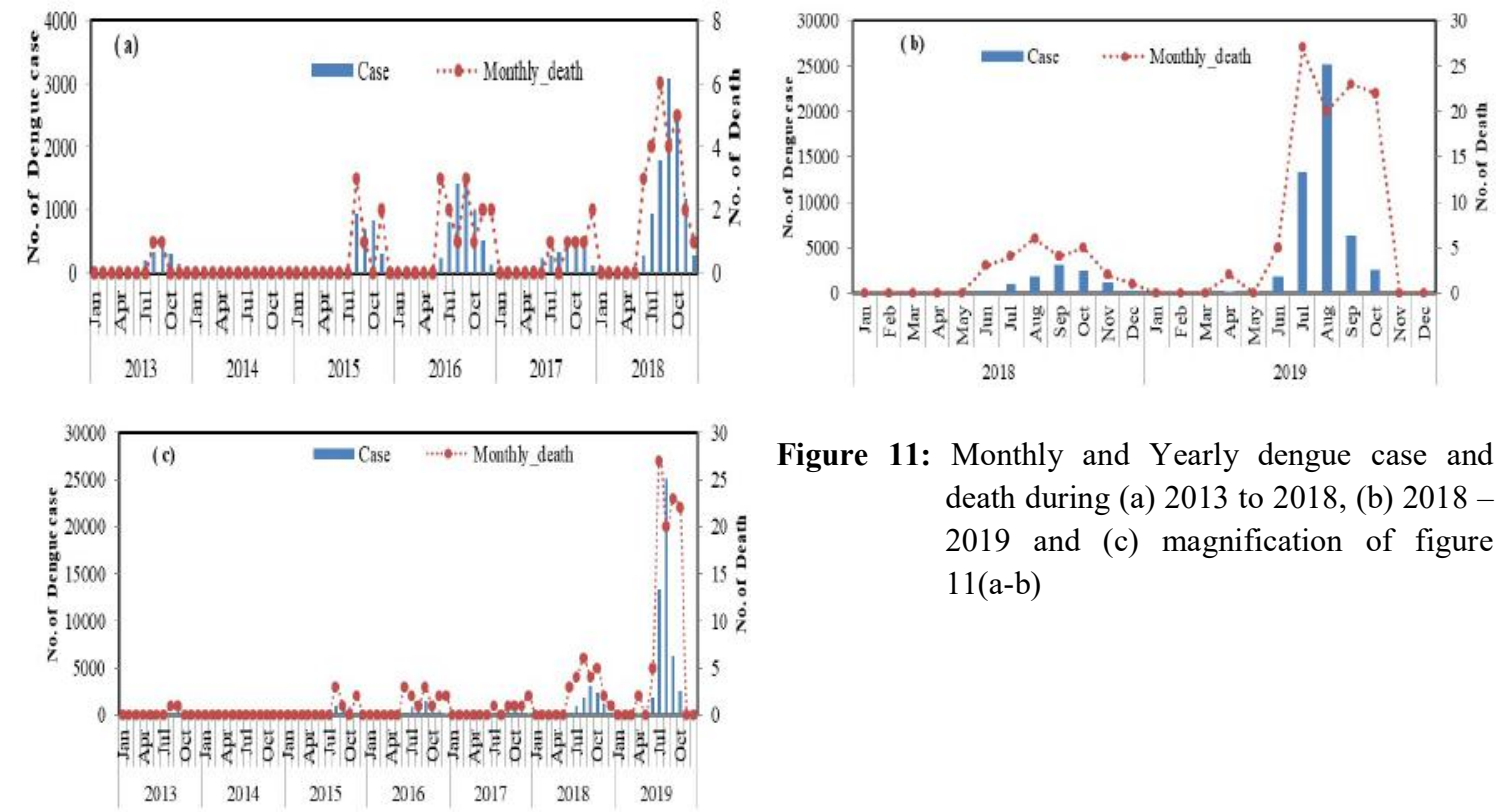

Figure 11: Monthly and Yearly dengue case and death during (a) 2013 to 2018 , (b) 2018 2019 and (c) magnification of figure $11(a-b)$

\section{CONCLUSIONS}

From the analysis the following conclusions can be drawn:

- The dengue incidence varies widely from year to year as well as season to season. Pre-monsoon rain, high temperature in January, intermittent rainfall in June, the previous year the latent condition of Aedes' larvae, and overall climate change are the cause of the dengue epidemic in 2019 of Dhaka city. The variation of the dengue effect also varies year to year which may be correlated with rainfall variation over Bangladesh.

- The weather conditions like the maximum temperature of $25-35^{\circ} \mathrm{C}$, minimum temperature $22-28^{\circ} \mathrm{C}$, humidity (70-90) \%, rainfall $20 \mathrm{~mm}$ or less are too much support for the dengue epidemic.

- Densely populated areas and lack of awareness are responsible for abnormal rising dengue events over Dhaka city in 2019.

\section{REFERENCES}

Arifa Akram, 2019. Bangladesh Journal of Infectious Disease, 6(1), 1-2, doi: https://doi.org/10.3329/ bjid. v6i1.42627.

Chee-Fu Y., Lee K.S., Thein T. L., Tan L. K., Gan V. C., Wong J. G. X., Lye D. C., Ng L. C., and Leo Y. S., 2015. Dengue Serotype-Specific Differences in Clinical Manifestation, Laboratory Parameters and Risk of Severe Disease in Adults, Singapore, The American Society of Tropical Medicine and Hygiene, Am J Trop Med Hyg, 92(5), doi: 10.4269/ajtmh.14-0628.

Dengue virus net.com, http://www.denguevirusnet.com/aedes-aegypti.html.

DGHS-4 ${ }^{\text {th }}$ edition, 2018. National Guideline for Clinical Management of Dengue Syndrome, World Health Organization, country office in Bangladesh, National Malaria Elimination \& Aedes Transmitted 
Disease Control Proggram, Disease Control Unit, Directorate General of Health Services (DGHS) Mohakhali, Dhaka-1212, $4^{\text {th }}$ edition 2018, 1-84.

Dhaka Population 2020. World Population Review, http://worldpopulationreview.com/world-cities/dhakapopulation.

Emiliana M. Silva, Jonas N. Conde, Diego Allonso, Gustavo T. Ventura, Diego R. Coelho, Pedro Henrique Carneiro, Manuela L. Silva, Marciano V. Paes, Kíssila Rabelo, Gilberto Weissmuller, Paulo Mascarello Bisch \& Ronaldo Mohana-Borges, 2019. Dengue virus nonstructural 3 protein interacts directly with human glyceraldehyde3-phosphate dehydrogenase (GAPDH) and reduces its glycolytic activity, Scientific Reports 9:2651, doi.org/10.1038/s41598-019-39157-7, 1-19.

Hossain, M. S., Siddiqee M. H., Siddiqi U. R., Raheem Akter R., and Hu W., 2020. Dengue in a crowded megacity: Lessons learnt from 2019 outbreak in Dhaka, Bangladesh, PLoS neglected tropical diseases, 14(8), e0008349.

Hossain, M.P., Zhou W., Ren C., Marshall J., and Yuan H. Y., 2020. Determining the effects of preseasonal climate factors toward dengue early warning system in Bangladesh, medRxiv.

Leisure, Mosquito Demystified, Home, Interesting facts about mosquitoes, How high can a mosquito fly? http://www.how2lab.com/leisure/mosquito.php.

Li, Y. Q., Lu Y., Xiang H, Yu X., and Liu S., 2020. Effects of ambient temperature and precipitation on the risk of dengue fever: a systematic review and updated meta-analysis Environment research, 110043.

Mamun, M. A., Misti J. M., Griffiths M. D., and Gozal D., 2019. The dengue epidemic in Bangladesh: risk factors and actionable items, The Lancet, 394(10215), 2149-2150.

Mutsuddy, P., Tahmina Jhora S., Shamsuzzaman A. K. M., Kaisar S. M., and Khan M. N. A., 2019. Dengue situation in Bangladesh: An epidemiological shift in terms of morbidity and mortality, Canadian Journal of infectious Diseases and Medical Microbiology.

Noor, R., 2020. Reemergence of dengue virus in Bangladesh: Current fatality and the required knowledge. TzuChi Medical Journal, 32(3), 227.

Quamrul, H. S. M., Mallik M. A. K., Akhter Md. A. E., and Chowdhury M. A. M., 2015. Trend analysis and spatial distribution of monsoon precipitation over Bangladesh during 1951-2012, Journal of Engineering Science 06(1\&2), 75-80.

Quora, How high can a dengue mosquito fly? https://www.quora.com/How-high-can-a-dengue-mosquito-fly

Rahman, M.S., Karamehic-Muratovic A., Baghbanzadeh M., Amrin M., Zafar S., Rahman N. N., Shirina S. U., and Haque U., 2020. Climate change and dengue fever Knowledge, attitudes and practices in Bangladesh: a social media-based cross-sectional survey, Transactions of the Royal Society of Tropical Medicine and Hygiene.

ResearchGate.https://www.researchgate.net/figure/Location-and-administrative-map-of-Dhaka-city-13_fig1_ 320292356.

Riad, M. M. H., Cohnstaedt L.W., \& Scoglio C. M., 2020. Risk assessment of vector-borne disease transmission using spatiotemporal network model and climate data with an application of dengue in Bangladesh, MedRxiv.

Shil, P., 2019. Rainfall and dengue occurrences in India during 2010-2016, Biomedical Research Journal, 6(2), 56.

Suleman Atique, Ta-Chien Chan, Chien-Chou Chen, Chien-Yeh Hsu, Somia Iqtidar, Valérie R. Louis, Syed A. Shabbir, Ting-Wu Chuang, 2018. Investigating spatio-temporal distribution and diffusion patterns of the dengue outbreak in Swat, Pakistan, Journal of Infection and Public Health, 11(4), 550-557.

Syed Abdul Kader, Sonia Afrin Rob, 2020. Incidence and Pattern of Clinical Dengue Cases among Travelers and Non-Travelers in a District of Bangladesh, Bangladesh Journal of Infectious Diseases, 7(1), 3-7.

www. Scitable by nature Education, A collaborative learning space for science, Library page, Concept Dengue Viruses, The Dengue serotypes, https://www.nature.com/scitable/topicpage/dengue-viruses-22400925.

Youngjo C., Tang C. S., McIver L., Hashizume M., Chan V., Abeyasinghe R. R., Iddings S., and Huy R., 2016. Effects of weather factors on dengue fever incidence and implications for interventions in Cambodia, BMC Public health, doi: 10.1186/s12889-016-2923-2, pp 1-7.

Yusha Araf, M., Ullah A., Faruqui N. A., Mowna S. A., Hossain D., and Prium B. S., 2020. Dengue Epidemic is a Global Recurrent Crisis: Review of the Literature.

(C) 2020 The Authors. Journal of Engineering Science published by Faculty of Civil Engineering, Khulna University of Engineering \& Technology. This is an open access article under the terms of the Creative Commons AttributionNonCommercial-NoDerivatives License, which permits use and distribution in any medium, provided the original work is properly cited, the use is non-commercial and no modifications or adaptations are made. 